\title{
ACTIVATION OF NATURAL CYTOTOXIC ACTIVITY AND CONCOMITANT REDUCTION OF TRIGLYCERIDE CONTENT OF MURINE SPLEEN, TREATED WITH AN ANTITUMOR ANTIBIOTIC, ASCOFURANONE
}

\author{
Junji Magae, Mitsuyuki Hotta, Kazuo Nagai, Seikichi Suzuki, \\ Kunio Ando, Makari Yamasaki and Gakuzo Tamura \\ Department of Agricultural Chemistry, University of Tokyo, \\ Yayoi, Bunkyo-ku, Tokyo 113, Japan
}

(Received for publication September 30, 1985)

\begin{abstract}
Ascofuranone (AF) elevated natural cytotoxic activity of spleen when it was administered intraperitoneally to male mice. The elevation was observed both in low and high responder mice. AF-activated splenocytes lysed NK-resistant tumor cells, FM3A, P388 and sarcoma 180 cells as well as NK-sensitive YAC-1 cells. However, AF suppressed other lymphatic functions such as mitogenic responses and interleukin 2 production. Because AF did not activate splenic NK activity in vitro, the activation is assumed to be caused by a host-mediated process. One of the possibilities is modulation of the lipid metabolism of splenocytes. Thus, we examined splenic lipid contents and revealed that AF decreased splenic triglycerides without affecting other lipids. In contrast, the antibiotic significantly increased triglyceride in muscle.
\end{abstract}

Ascofuranone (AF) was isolated from a phytopathogenic fungus Ascochyta viciae as a hypolipidemic substance, having prenyl-phenolic structure ${ }^{1)}$. It reduces serum lipid level of experimental animals after oral administration ${ }^{2)}$. It also modulates lipid metabolism of leukemia L5178Y cells in vitro and alters membrane properties ${ }^{33}$.

Recently, we reported its antitumor activity against experimental tumors, including L1210, sarcoma 180 and Ehrlich carcinoma. A characteristic of the antitumor activity is that AF is effective with pretreatment as well as with post-treatment, indicating that the antitumor activity is host-mediated $^{4)}$. As AF modulates lipid metabolism, the host-mediated antitumor activity may be caused by modulating lipid metabolism.

In this report, we studied the effects of AF on the host immune system and revealed an activation of splenic natural cytotoxicity and concomitant reduction of the triglyceride content by AF.

\section{Materials and Methods}

Mice

$\overline{\mathrm{C} 3 \mathrm{H}} / \mathrm{He}, \mathrm{BALB} / \mathrm{c}, \mathrm{BDF} 1, d d \mathrm{Y}$ and $\mathrm{C} 57 \mathrm{BL} / 6,6 \sim 10$ weeks old male mice were purchased from Shizuoka Experimental Farm (Hamamatsu). Commercial pellet diet (CE-2, Clea, Japan, Ltd., Tokyo) and tap water were fed ad libitum.

\section{Chemicals}

Purified ascofuranone (AF) was supplied by Chugai Pharmaceutical Co., Ltd. (Tokyo). For in vitro studies, AF was dissolved in methanol at $10 \mathrm{mg} / \mathrm{ml}$ and diluted to appropriate concentration with medium. For in vivo administration, AF was suspended in $0.5 \%$ Tween 80 dissolved in phosphatebuffered saline (PBS, pH 7.4) with the aid of a Teflon homogenizer. RPMI1640 medium (Nissui Seiyaku Co., Tokyo) supplemented with $5 \%$ fetal bovine serum (FBS, Flow Laboratories, North 
Ryde, N.S.W. Australia), $5 \times 10^{-5} \mathrm{M}$ 2-mercaptoethanol, $50 \mu \mathrm{g} / \mathrm{ml}$ kanamycin and $5 \mathrm{~mm}$ HEPES was used for cell culture. EAGLE's MEM (Nissui Seiyaku Co., Tokyo) without serum was used to wash the cells.

\section{Assay of Cytotoxic Activity}

A suspension of spleen cells treated with ammonium chloride to remove erythrocytes was prepared as described previously ${ }^{4}$. Target cells in late log phase were collected and incubated for 45 minutes in $50 \mu \mathrm{l}$ of $1 \mathrm{mCi} / \mathrm{ml}\left[{ }^{51} \mathrm{Cr}\right]$ sodium chromate saline solution (New England Nuclear, Boston, MA). After three washes with MEM, $1 \times 10^{4}$ target cells were incubated with effector cells in $200 \mu$ l volume at $37^{\circ} \mathrm{C}$ in a flat-bottomed microplate well (Nunc, Roskilde, Denmark). After 4-hour incubation, the radioactivity in $100 \mu \mathrm{l}$ of supernatant was determined. \% Lysis was calculated by the following equation:

$\%$ Lysis $=($ Experimental release - Spontaneous release $) /($ Maximum release - Spontaneous release $)$ Spontaneous and maximum releases were determined by culturing the target cells in medium and in $0.5 \%$ sodium dodecyl sulfate solution, respectively.

Production of Interleukin 2 (IL 2) and its Assessment

Five million splenocytes in $1 \mathrm{ml}$ volume in a flat-bottomed 16-mm diameter plastic well (Nunc, Roskilde, Denmark) were cultured in the presence of $5 \mu \mathrm{g} / \mathrm{ml}$ concanavalin A (con A, Sigma Chem., St. Louis, MO). After 24 -hour culture at $37^{\circ} \mathrm{C}$, the supernatants were collected and centrifuged to remove contaminated cells. They were stored at $-20^{\circ} \mathrm{C}$ until used. IL 2 activity in the supernatant was measured by a proliferative response of thymocytes in the presence of suboptimal concentration of phytohemaggultinin (PHA). One million $\mathrm{C} 3 \mathrm{H} / \mathrm{He}$ thymocytes prepared in the same manner as splenocytes except the removal of erythrocytes, in $200 \mu \mathrm{l}$ volume in a flat-bottomed microplate well were cultured in the presence of $10 \%$ supernatant and $1 \mu \mathrm{g} / \mathrm{ml}$ PHA (Wellcome, Bechenham, UK). After a 44-hour culture, each well was pulsed with $0.5 \mu \mathrm{Ci}\left[{ }^{3} \mathrm{H}\right]$ thymidine (New England Nuclear, Boston, MA). Cultures were harvested 4-hour later by an automatic cell harvester.

Extraction and Estimation of Lipid Content

About $100 \mathrm{mg}$ slices of muscle or liver was carefully dissected and homogenized by a glass homogenizer in 20 volumes of chloroform - methanol (2:1). After 20 hours, the precipitate was removed by filtration and the extract was stored at $-20^{\circ} \mathrm{C}$ until used. Blood was removed from the hearts of ether-anesthetized mice, using a heparinized syringe and plasma was obtained by centrifugation. Lipids in extracts and plasma were determined by the following assay methods: Triglycerides by VAN HANDEL method ${ }^{5)}$; phospholipids by ZILVERSMIT method $^{8)}$; free fatty acid by ITAYA-Ui method ${ }^{\text {) }}$ and total cholesterol by ZuRKowski's method ${ }^{8)}$.

\section{Results}

\section{Activation of Natural Cytotoxic Activity of Spleen}

AF augmented splenic natural cytotoxic activity when administered intraperitoneally 7, 5 and 3 days before the assay (Fig. 1). Activation was observed with all the effector-to-target (E/T) ratios tested. Cytotoxic capacity of splenocytes reached to plateau level at $\mathrm{E} / \mathrm{T}=200$ and $\mathrm{AF}$ elevated the plateau level. This suggests that the activity of each effector cell was amplified. AF stimulated cytotoxic activity in a dose-dependent manner and a relatively high dose was required for significant activation. $\mathrm{LD}_{50}$ of $\mathrm{AF}$ was about $800 \mathrm{mg} / \mathrm{kg}$.

As shown in Table 1, normal mice of $\mathrm{C} 3 \mathrm{H} / \mathrm{He}$ and $\mathrm{C} 57 \mathrm{BL} / 6$ strains had higher endogenous cytotoxic activity than $d d \mathrm{Y}, \mathrm{BALB} / \mathrm{c}$ and BDF1. AF activated splenic cytotoxic activity of both types of mice. Maximum activation was observed with BDF1 mice, which reached more than 4.5 -fold over the control. In addition, splenocytes from AF-treated mice were able to lyse natural killer (NK)resistant tumor cells (P388, FM3A and sarcoma 180) as well as NK-sensitive YAC-1 (Table 2). It is 
Fig. 1. Activation of splenic cytotoxic activity by AF.

Splenocytes from three mice treated ip with

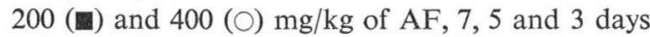
before the assay were incubated with ${ }^{51} \mathrm{Cr}$-labeled YAC- 1 cells at the indicated $\mathrm{E} / \mathrm{T}$ ratios. Control mice (-) received only the vehicle.

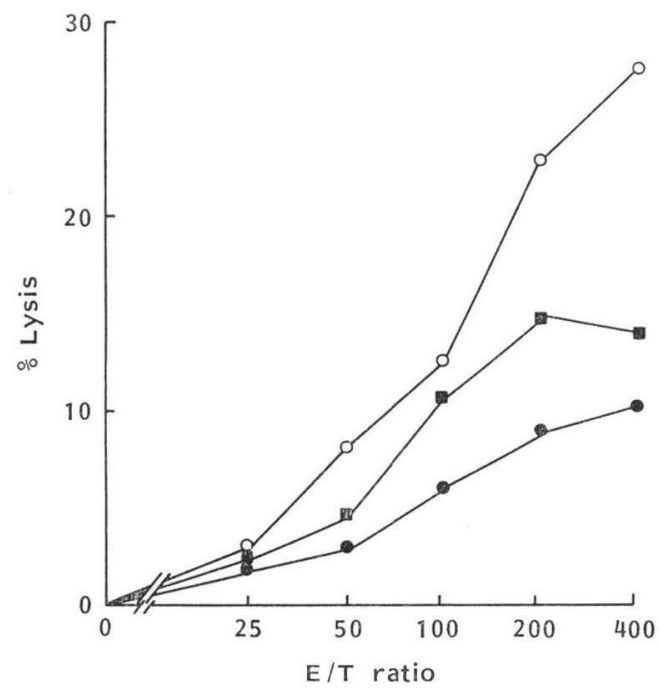

also noted that they were able to lyse the cells of sarcoma (sarcoma 180) and carcinoma (FM3A) as well as lymphoma (YAC-1).

\section{In Vitro Effect of AF on Splenic Cytotoxic Activity}

Some substances that activate NK cells in vivo also activate them in vitro ${ }^{9)}$. However, preincubation of splenocytes with AF had no influence on cytotoxic activity. Rather, high concentration of AF suppressed it (Table 3). In addition, cytotoxicity of splenocytes was not elevated when cytotoxic assay was performed in the presence of AF (data not shown). Therefore, activation of splenic cytotoxicity by $\mathrm{AF}$ is assumed to be host-mediated.
Table 1. Activation of splenic cytotoxic activity of AF-administered mice.

\begin{tabular}{lcc}
\hline \multirow{2}{*}{ Mouse strain } & \multicolumn{2}{c}{$\%$ Lysis } \\
\cline { 2 - 3 } & Control & AF-treated \\
\hline BALB/c & 7.1 & $32.0^{\mathrm{b}}(451)^{\mathrm{a}}$ \\
$\mathrm{BDF} 1$ & 10.1 & $47.1^{\mathrm{b}}(466)$ \\
$\mathrm{C} 3 \mathrm{H} / \mathrm{He}$ & 24.3 & $65.8^{\mathrm{b}}(271)$ \\
$\mathrm{C} 57 \mathrm{BL} / 6$ & 19.1 & $40.0^{\mathrm{b}}(209)$ \\
$d d \mathrm{Y}$ & 7.5 & $34.1^{\mathrm{b}}(455)$
\end{tabular}

One million splenocytes from three mice treated ip with $200 \mathrm{mg} / \mathrm{kg}$ of $\mathrm{AF}, 7,5$ and 3 days before the assay were cultured with $1 \times 10^{4}{ }^{51} \mathrm{Cr}$-labeled YAC-1 cells in triplicate cultures. Four hours later, the radioactivity released in the supernatant was determined. Control mice received only the vehicle. Standard deviation of each assay was within ten percent of average value.

a Figures in parentheses represent $\%$ to control value.

b Statistically significant by Student's test at $P<$ 0.001 .

Table 2. Target spectrum of AF-activated splenocytes.

\begin{tabular}{lcc}
\hline \multirow{2}{*}{ Target cells } & \multicolumn{2}{c}{$\%$ Lysis } \\
\cline { 2 - 3 } & Control & AF-treated \\
\hline FM3A & 7.8 & $16.6^{\mathrm{b}}(212)^{\mathrm{a}}$ \\
Sarcoma 180 & 8.9 & $24.3^{\mathrm{b}}(274)$ \\
P388 & 5.1 & $22.0^{\mathrm{b}}(433)$ \\
YAC-1 & 33.6 & $64.1^{\mathrm{b}}(191)$ \\
\hline
\end{tabular}

One million splenocytes from three $\mathrm{C} 3 \mathrm{H} / \mathrm{He}$ mice treated ip with $200 \mathrm{mg} / \mathrm{kg}$ of $\mathrm{AF}, 7,5$ and 3 days prior the assay were cultured with $1 \times 10^{4}$ ${ }^{51} \mathrm{Cr}$-labeled target cells in triplicate cultures. Four hours later, the radioactivity in the supernatant was determined. Control mice received only the vehicle. Standard deviation of each assay was within ten percent of control value.

a Figures in parentheses represent $\%$ to control value.

b Statistically significant by Student's test at $P<$ 0.05 .

Major cell population that contribute to splenic natural cytotoxicity is NK cells and typical intrinsic activators of $\mathrm{NK}$ cells are interleukin 2 (IL 2) and interferon (IFN) ${ }^{10)}$. As T cells produce both factors, activation of $\mathrm{T}$ cells would result in the activation of NK cells. However, splenocytes from AF-treated mice showed poorer responses to PHA and con A, which are polyclonal activators of $\mathrm{T}$ cells. In fact, splenocytes from AF-treated mice produced less IL 2 than the control in response to con A (Table 4). The similar results were obtained when IL 2 activity was determined by IL 2 dependent lymphocyte line. Therefore, it is likely that AF activated splenic cytotoxicity through 
Table 3. Inhibition of splenic cytotoxic activity by the preincubation with AF.

\begin{tabular}{cc}
\hline $\mathrm{AF}(\mu \mathrm{g} / \mathrm{ml})$ & $\%$ Lysis \\
\hline 0 & 36.9 \\
0.6 & 46.5 \\
1.3 & 32.5 \\
2.5 & 34.0 \\
5 & $5.0^{\mathrm{a}}$ \\
10 & $0^{\mathrm{a}}$ \\
\hline
\end{tabular}

Ten million $\mathrm{C} 3 \mathrm{H} / \mathrm{He}$ splenocytes per $\mathrm{ml}$ were cultured in the presence of indicated concentration of AF for 24 hours. Cells were washed three times with $\mathrm{MEM}$ and $1 \times 10^{\circ}$ viable cells were cultured with $1 \times 10^{4}{ }^{51} \mathrm{Cr}$-labeled YAC-1 cells in triplicate assays. Four hours later, radioactivity in the supernatant was determined. Standard deviation of each assay was within ten percent of control value.

a Statistically significant by Student's test at $P<$ 0.001 .

other mechanism than the activation of $\mathrm{T}$ cells.
Table 4. AF-treated mice is prevented to release IL 2 in response to con $A$.

\begin{tabular}{|c|c|}
\hline Group & $\begin{array}{c}{\left[{ }^{3} \mathrm{H}\right] \text { Thymidine }} \\
\text { incorporation }{ }^{\mathrm{a}}(\mathrm{cpm})\end{array}$ \\
\hline \multicolumn{2}{|l|}{ Experiment 1} \\
\hline Control & $42,742 \pm 2,125$ \\
\hline AF-treated & $33,824 \pm 250^{\mathrm{c}}$ \\
\hline \multicolumn{2}{|l|}{ Experiment 2} \\
\hline Control & $40,179 \pm 7,562$ \\
\hline AF-treated & $16,032 \pm 2,281^{\circ}$ \\
\hline Medium $^{\text {b }}$ & $10,524 \pm 1,926$ \\
\hline
\end{tabular}

Five million $\mathrm{C} 3 \mathrm{H} / \mathrm{He}$ splenocytes per $\mathrm{ml}$ from three mic etreated with $200 \mathrm{mg} / \mathrm{kg}$ of $\mathrm{AF}, 7,5$ and 3 days before the assay were cultured with $5 \mu \mathrm{g} / \mathrm{ml}$ con A for 24 hours. The IL 2 activity in the supernatant was assessed as described in Materials and Methods. Control mice received only the vehicle.

a Mean \pm SD of triplicate assays.

b Incorporation of $\left[{ }^{3} \mathrm{H}\right]$ thymidine into thymocytes in the absence of exogenous IL 2.

c Statistically significant by Student's test at $P<$ 0.001 .

\section{Effects of AF on Splenic Lipid Content}

As AF affects lipid metabolism both in vivo and in vitro, this property could be related to activation of splenic natural cytotoxic activity. We, therefore, estimated the lipid contents of spleens from AF-treated mice to ascertain whether AF also affects the lipid metabolism of the lymphoid organ. The result is shown in Table 5. AF significantly reduced splenic triglycerides (TG) in a dose dependent manner whereas no influence on other major lipid content, free fatty acids (FFA), phospholipids (PL) and cholesterol, was observed. To ascertain whether the influence on TG content is specific for spleen, TG content of serum and liver was also estimated and it was found to be affected only slightly. However, muscle TG increased more than two-fold (Table 6), indicating that AF modulates lipid metabolism systemically.

\section{Discussion}

As lipid is one of the major components of plasma membrane, it greatly affects the property of the membrane ${ }^{11,12)}$. Immunological interactions take place on the plasma membrane. Therefore, cellular lipid metabolism is assumed to have profound influence on an immune network. In addition, alteration of phospholipid metabolism is reported in various immune reactions including activation of NK cells ${ }^{13)}$, macrophages ${ }^{14)}$ and polymorphonuclear leukocytes $(\mathrm{PMN})^{15)}$, which are possible mediators of natural cytotoxic activity of spleen. Therefore, it is interesting to study how an immune network is affected by $\mathrm{AF}$ which modulates lipid metabolism both in vivo and in vitro.

We found that AF reduced splenic TG content concomitantly with the activation of natural cytotoxicity. Further study is needed to explore the relationship between activation of natural cytotoxic activity and the reduction of TG content in spleen of AF-treated mice. However, we have obtained a preliminary result that an immunopotentiator, OK-432, which activates splenic NK activity ${ }^{16)}$, also greatly affects splenic lipid metabolism. Our results obtained in the present report strongly suggest that lipid metabolism and an immune system intimately correlate with each other.

Possible populations mediating splenic natural cytotoxicity include NK cells, macrophages and PMNs. In 4-hour cytotoxic assay, however, cytotoxic activity may be mainly contributed by NK cells 
Table 5. Effect of AF on splenic lipid contents.

\begin{tabular}{ccccc}
\hline \multirow{2}{*}{$\begin{array}{c}\mathrm{AF} \\
(\mathrm{mg} / \mathrm{kg})\end{array}$} & TG & LFA & PL & Cholesterol \\
\cline { 2 - 5 } & $6.27 \pm 0.14$ & $12.2 \pm 1.9$ & $0.68 \pm 0.02$ & $1.00 \pm 0.03$ \\
0 & $4.84 \pm 0.21^{\mathrm{b}}$ & $11.8 \pm 3.5$ & $0.62 \pm 0.05$ & $0.95 \pm 0.01$ \\
100 & $(77)$ & $(97)$ & $(91)$ & $(95)$ \\
& $5.15 \pm 0.20^{\mathrm{b}}$ & $9.4 \pm 7.0$ & $0.60 \pm 0.01^{\mathrm{b}}$ & $0.93 \pm 0.07$ \\
200 & $(82)$ & $(77)$ & $(89)$ & $(93)$ \\
& $4.32 \pm 0.44^{\mathrm{b}}$ & $12.7 \pm 2.4$ & $0.63 \pm 0.01^{\mathrm{b}}$ & $0.96 \pm 0.03$ \\
& $(69)$ & $(104)$ & $(91)$ & $(96)$ \\
\hline
\end{tabular}

Lipid was extracted from the spleens of three mice treated with indicated dose of AF, 7, 5 and 3 days before the sacrifice. Each lipid content was determined in the triplicate assays.

a Mean \pm SD. Figures in parentheses represent $\%$ to control value.

b Statistically significant by Student's test at $P<0.01$.

Table 6. Effect of AF on plasma, liver and muscle TG content.

\begin{tabular}{cccc}
\hline \multirow{2}{*}{$\begin{array}{c}\text { AF } \\
(\mathrm{mg} / \mathrm{kg})\end{array}$} & Triglyceride content ${ }^{\mathrm{a}}$ \\
\cline { 2 - 4 } & Plasma $(\mathrm{mg} / \mathrm{dl})$ & Liver $(\mathrm{mg} / \mathrm{g})$ & Muscle $(\mathrm{mg} / \mathrm{g})$ \\
\hline 0 & $34.2 \pm 4.4$ & $1.38 \pm 0.20$ & $7.8 \pm 0.6$ \\
100 & $27.9 \pm 1.3$ & $1.55 \pm 0.15$ & $13.9 \pm 0.9^{\mathrm{b}}$ \\
& $(82)$ & $(112)$ & $(178)$ \\
200 & $47.2 \pm 2.2$ & $1.69 \pm 0.12$ & $21.4 \pm 1.4^{\mathrm{b}}$ \\
& $(138)$ & $(122)$ & $(274)$ \\
400 & $29.9 \pm 2.3$ & $1.30 \pm 0.10$ & $12.8 \pm 0.3^{\mathrm{b}}$ \\
& $(87)$ & $(94)$ & $(164)$ \\
\hline
\end{tabular}

Lipid content of tissues and plasma from three mice treated with indicated dose of AF, 7, 5 and 3 days before the sacrifice, was determined in triplicate assays.

a Mean \pm SD. Figures in parentheses represent $\%$ to control value.

b Statistically significant by Student's test at $P<0.001$.

because the expression of complete cytotoxicity of macrophages ${ }^{17)}$ or $\mathrm{PMNs}^{18)}$ requires more than 10 hours of incubation. Furthermore, AF-activated splenocyte preferentially lyse NK-sensitive target, YAC-1 cells. However, they also attacked the tumor cells which belong to the NK-resistant group. In our preliminary results, the cytotoxic effects belonged to the non-adherent population, when spleen cells were separated into adherent and non-adherent populations by passing through a Sephadex G-10 column. However, the method could not completely exclude macrophages and especially neutrophiles when cell populations were morphologically determined by Giemsa staining. Therefore, our present results cannot completely rule out the possibility of participation of macrophages and PMNs. In fact, we found that PMNs increased in the splenocytes of AF-treated mice (MAGAE, J.; K. NAGAI \& G. TAMURA: unpublished results). Expansion of target spectrum by AF might be due to the PMNs. Final characterization of effector cells will be accomplished by application of specific antibody.

\section{Acknowledgment}

This work was supported in part by a Grant-in-Aid for cancer research from the Ministry of Education, Science and Culture, Japan. We thank Ms. Y. MAGAE for her help in preparation of this manuscript.

\section{References}

1) Sasaki, H.; T. Hosokawa, M. Sawada \& K. Ando: Isolation and structure of ascofuranone and ascofuranol, antibiotics with hypolipidemic property. J. Antibiotics 26: 676 680, 1973

2) Sawada, M.; T. Hosokawa, T. OKutomi \& K. Ando: Hypolipidemic property of ascofuranone. J. Antibiotics 26: $681 \sim 686,1973$ 
3) Magae, J.; K. Nagai, K. Ando, M. Yamasaki \& G. Tamura: Effects of an antitumor agent, ascofuranone, on the macromolecular syntheses of intact cells. J. Antibiotics 36: 892 899, 1983

4) Magae, J.; T. Hosokawa, K. Ando, K. Nagai \& G. Tamura: Antitumor protective property of an isoprenoid antibiotic, ascofuranone. J. Antibiotics 35: 1547 1552, 1982

5) Van Handel, E.; D. B. Zilversmit \& K. Bowman: Micromethod for the direct determination of serum triglyceride. J. Lab. Clin. Med. 50: 152 156, 1957

6) Zilversmit, D. B. \& A. K. DAvis: Microdetermination of plasma phospholipids by trichloroacetic acid precipitation. J. Lab. Clin. Med. 35: 155 160, 1950

7) ItAya, K. \& M. Ui: Colorimetric determination of free fatty acids in biological fluids. J. Lipid Res. 6: $16 \sim 20,1965$

8) Zurkowski, P.: A rapid method for cholesterol determination with a single agent. Clin. Chem. 10: $451 \sim 453,1964$

9) Saijo, N.; A. Ozaki, Y. Beppu, N. Irimajiri, M. Shibuya, E. Shimizu, T. Takizawa, T. Taniguchi \& A. Hoshi: In vivo and in vitro effects of Nocardia rubra cell wall skeleton on natural killer activity in mice. Jpn. J. Cancer Res. (Gann) 74: 137 142, 1983

10) Kuribayashi, K.; S. Gillis, D. E. Kern \& C. S. Henny: Murine NK cell cultures: Effect of interleukin2 and interferon on cell growth and cytotoxic reactivity. J. Immunol. 126: 2321 2327, 1981

11) InBer, M. \& M. ShinitzKy: Increase of cholesterol level in the surface membrane of lymphoma cells and its inhibitory effects on ascites tumor development. Proc. Natl. Acad. Sci. U.S.A. 71: 2128 2130, 1974

12) Hirata, F. \& J. Axelrod: Enzymatic methylation of phosphatidylethanolamine increases erythrocyte membrane fluidity. Nature 275: 219 220, 1978

13) Hoffman, T.; F. Hirata, P. Bougnoux, B. A. Frazer, R. H. Goldhalb, R. B. Herberman \& J. Axelrod: Phospholipid methylation and phospholipase $\mathrm{A}_{2}$ activation in cytotoxicity by human natural killer cells. Proc. Natl. Acad. Sci. U.S.A. Biol. Sci. 78: 3839 3843, 1981

14) Homma, Y.; K. Onozaki, T. Hashimoto, Y. Nagai \& T. Takenawa: Differential activation of phospholipids metabolism by formylated peptide and ionophore A23187 in guinea pig peritoneal macrophages. J. Immunol. 129: 1619 1626, 1982

15) Gil, M. G.; F. Alonso, M. SÁnchez-Crespo \& J. M. Mato: Inhibition of phospholipid methyltransferase during zymosan induced secretion of platelet-activating factor in human polymorphonuclear leukocytes. Biochem. Biophys. Res. Commun. 101: 740 748, 1981

16) Oshimi, K.; S. Kano, F. TAKAKu \& K. OKumura: Augmentation of mouse natural killer cell activity by a streptococcal preparation, OK-432. J. Natl. Cancer Inst. 65: 1265 1269, 1980

17) Kurisu, M.; M. YamazaKi \& D. Mizuno: Induction of macrophage-mediated tumor lysis by the lectine wheat germ agglutinin. Cancer Res. 40: 3798 3803, 1980

18) Tsunawaki, S.; H. Oshima, D. Mizuno \& M. Yamazaki: Induction of polymorphonuclear leukocytemediated cytolysis by wheat germ agglutinin and antitumor antibody. Jpn. J. Cancer Res. (Gann) 74 : $258 \sim 264,1983$ 